$\ddot{\mathbb{1}}$ STFM SOCIETY OF TEACHERS OF From the Society of Teachers FAMILY MEDICINE of Family Medicine

Ann Fam Med 2019;17:183-185. https://doi.org/10.1370/afm.2375.

\section{PRELIMINARY RESULTS OF THE ABFMI STFM PRECEPTING PERFORMANCE IMPROVEMENT PILOT}

The Society of Teachers of Family Medicine (STFM) and the American Board of Family Medicine (ABFM) have wrapped up a pilot program that offers Performance Improvement continuing certification credit (previously MOC Part IV) to ABFM diplomates who provide personal instruction, training, and supervision to a medical student or resident and who participate in a teaching improvement activity.

Forty-two academic units (Sponsors) were selected to participate through an application process. Thirtythree completed the requirements of the program and submitted a final report:

- Albany Medical College Department of Family and Community Medicine

- Albert Einstein College of Medicine, Department of Family and Social Medicine/Montefiore Medical Center

- Baylor College of Medicine, Department of Family and Community Medicine

- Cook County Family Medicine Residency, Chicago, IL

- Donald and Barbara Zucker School of Medicine at Hofstra/Northwell, Department of Family Medicine

- Emory University, Department of Family \& Preventive Medicine, Undergraduate Medical Education Division

- Florida Atlantic University, Charles E. Schmidt College of Medicine

- Florida International University, Herbert Wertheim College of Medicine, Department of Humanities, Health, and Safety

- Health Alliance - Fitchburg Family Practice Residency, Fitchburg, MA

- Medical University of South Carolina Family Medicine Residency/Trident Medical Center, Charleston, SC

- New York Medical College, Family Medicine Residency at Saint Joseph's Medical Center, Yonkers, NY

- Offutt Air Force Base Family Medicine Residency, Nebraska

- Penn State College of Medicine, University Park Regional Campus

- Penn State Family and Community Medicine, Hershey, PA
- Quinnipiac University, Frank H. Netter MD School of Medicine

- Samaritan Family Medicine Residency, Corvallis, OR

- Temple University, Lewis Katz School of Medicine, Department of Family \& Community Medicine

- Texas Tech University Health Science Center-Amarillo

- UHS Wilson Family Medicine Residency, Johnson City, NY

- University of California, Davis, Department of Family and Community Medicine

- University of California, Riverside, School of Medicine

- University of Kentucky, Department of Family and Community Medicine

- University of Minnesota Family Medicine and Community Health Medical Student Education, Twin Cities Campus

- University of Missouri Health, Department of Family and Community Medicine

- University of North Carolina School of Medicine

- University of North Dakota Family Medicine Residency, Fargo, ND

- University of Oklahoma, OU-TU School of Community Medicine

- University of South Carolina, Greenville School of Medicine, Department of Family Medicine/Greenville Health System

- University of Texas RGV/DHR Family Medicine Residency

- University of Utah, Department of Family and Preventive Medicine

- Virginia Commonwealth University, Department of Family Medicine and Population Health

- Western Michigan University, Homer Stryker MD School of Medicine Family Medicine Residency, Kalamazoo

- West Virginia University, Eastern Campus and the Harpers Ferry Family Medicine Residency

During the pilot, which ran from April through December of 2018, Sponsors worked with preceptors to:

- Identify areas of teaching that needed improvement

- Create aims for improvement that included desired goals and timeframes for achieving improvement

- Conduct interventions

- Measure improvement

To receive the performance improvement credit, preceptors also had to complete 180 1:1 teaching hours. On the final report, Sponsors said that "with regard to providing incentive for teaching and implementing a performance improvement activity," 180 hours was about right $(67 \%)$, too much $(30 \%)$, or not enough (3\%). A few of those who said too much under- 
stood incorrectly that the 180 hours had to be completed during the 8 -month pilot project.

Sponsors reported that 353 preceptors were involved in the pilot; $30 \%$ were community preceptors and $70 \%$ were preceptors employed by academic units. On average, each Sponsor engaged 3 community preceptors and 8 employed faculty. As a whole, Sponsors were able to recruit or reengage 27 preceptors as a result of this project.

Learners included first-year students (4\%), secondyear students $(6 \%)$, third-year students (37\%), fourthyear students (9\%), and residents (44\%).

Sponsors generally felt that preceptors who participated in the project improved their teaching performance/skills/knowledge. There were project challenges, however, including:

- Resistance from preceptors about making time for interventions

- Difficulty getting buy-in from community preceptors

- Not enough time on the front end for Sponsors to understand all of the project details and to prepare appropriately

Sponsors recommended the following changes/ additions to the program:

- Provide materials to communicate the details to preceptors so there is no confusion about teaching hours necessary or specifics about the credit they can get

- Provide predetermined Performance Improvement projects that have been proven to work

- Share examples of assessment tools that have been used successfully

Several sponsoring institutions presented their results at the 2019 Conference on Medical Student Education. STFM and ABFM plan to publish results broadly.

\section{Opportunity for Family Medicine Departments and Residency Programs}

STFM and ABFM made minor tweaks to the program based on input from pilot Sponsors. Family medicine departments, residencies, chapters (or other units) can now apply to be Sponsors, helping preceptors earn Performance Improvement credit. More information and the application are available at https://theabfm. mymocam.com. To apply, register, then log in and look for the Precepting Performance Improvement Program application on the dashboard.

STFM is working on resources that will roll out this spring at www.stfm.org, including a "how-to" guide, a list of sample performance improvement projects, and an online interactive self-assessment tool linked

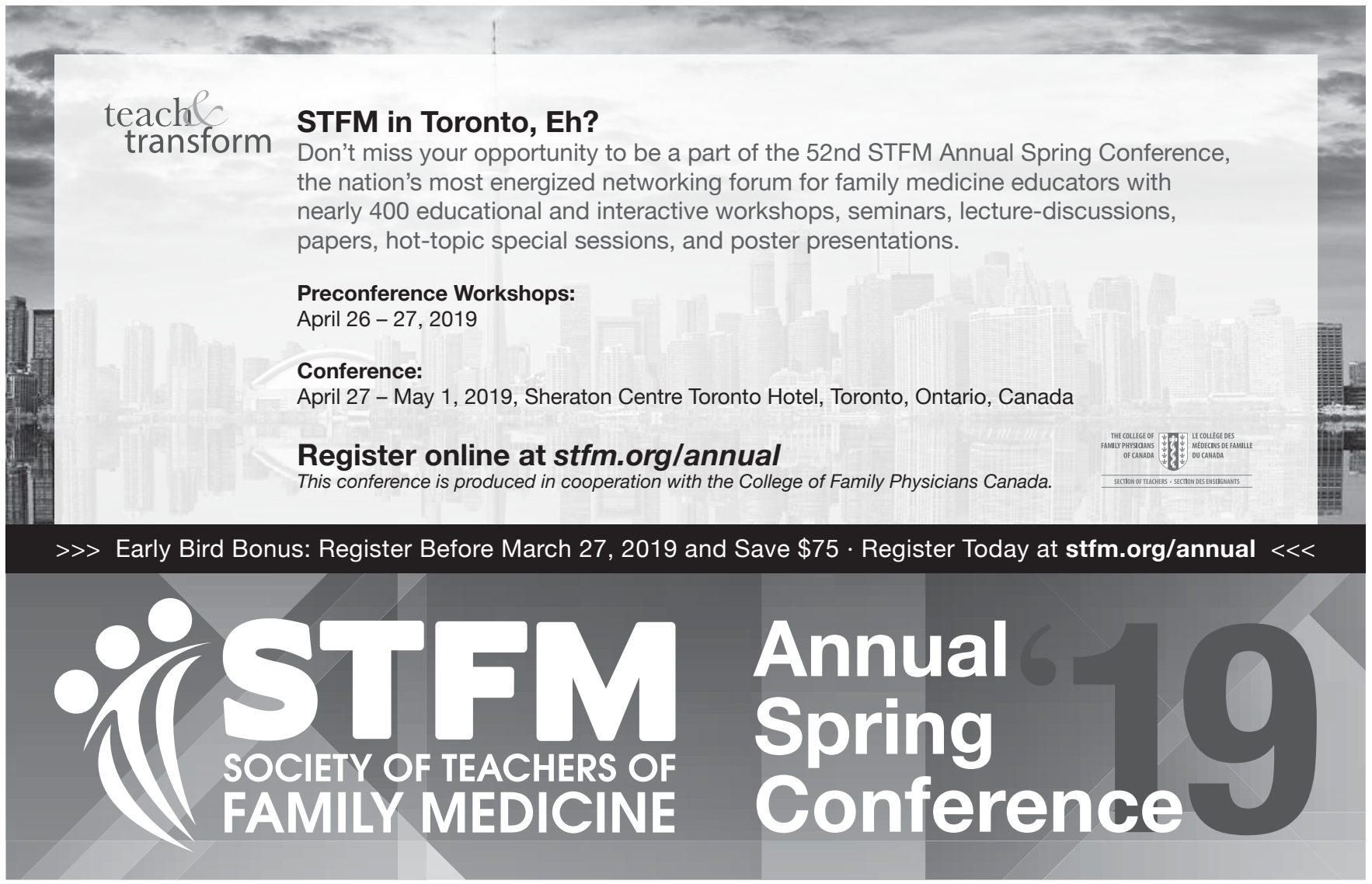

ANNALS OF FAMILY MEDICINE + WWW.ANNFAMMED.ORG + VOL. 17, NO. 2 + MARCH/APRIL 2019 
to resources on TeachingPhysician.org (subscription required for TeachingPhysician.org).

\section{Preceptor Expansion Initiative}

The STFM/ABFM Pilot Program was part of a Preceptor Expansion Initiative, being led by STFM, to address the shortage of clinical training sites for students. Five interprofessional, interdisciplinary teams are working on the following tactics:

- Tactic 1: Work with CMS to revise student documentation guidelines

- Tactic 2: Integrate interprofessional/interdisciplinary education into ambulatory primary care settings

- Tactic 3: Develop standardized onboarding process for students and preceptors \& integrate students into the work of ambulatory primary care settings in useful and authentic ways

- Tactic 4: Develop educational collaboratives across departments, specialties, professions, and institutions to improve administrative efficiencies

- Tactic 5: Promote productivity incentive plans that include teaching \& develop a culture of teaching in clinical settings

Learn more and follow the progress of the initiative at www.stfm.org/preceptorexpansion.

Disclaimer: All results in this article are preliminary.

Juliette Bradley and Mary Theobald

\section{ADFM Association of Departments of From the Association VISION, VOICE, LEADERSHIP Family Medicine}

\section{WHAT'S IN A NAME? DEPARTMENTS OF FAMILY MEDICINE AND ...}

Every department that is a member of the Association of Departments of Family Medicine includes the term "family medicine" in its title. Fewer than one-half our member departments, however, only have family medicine in their titles. Many titles acknowledge the other major elements of work being done by the teachers, clinicians, researchers, and learners who make up our departments. We are Departments of Family Medicine AND: Community Medicine; Community Health; Social Medicine; Public Health Sciences; Rural Health; Comprehensive Care; and Geriatric Medicine. One department even has the titular trifecta of Family, Community and Preventive Medicine (Table 1).

Some of these names reflect formal administration of degree programs in public health or residency programs in preventive medicine that have been integrated into our clinical departments. Some highlight specific mission areas, such as rural health or geriatrics. Others speak to the leadership role of many family medicine departments in "population health" as health systems move to value-based care models. (Recognizing that the term "population health" conjures up many different meanings, ADFM has recently taken on the challenge of developing a working definition; this will be the focus of a future commentary.)

Among departments that have names that include terms in addition to family medicine, the most common additional word is "community." This reflects a long history of the importance of community to the discipline of family medicine. About one-third of departments had "community" in their title a decade ago-many with this name dating back to their incep-

Table 1. Departments of Family Medicine AND...

\begin{tabular}{|c|c|c|c|c|}
\hline & \multicolumn{2}{|c|}{$\begin{array}{c}2011 \\
N=145\end{array}$} & \multicolumn{2}{|c|}{$\begin{array}{c}2018 \\
N=154\end{array}$} \\
\hline & No. & $\%$ & No. & $\%$ \\
\hline Family Medicine & 81 & $56 \%$ & 76 & $49 \%$ \\
\hline Family Practice & 1 & $1 \%$ & 0 & $0 \%$ \\
\hline Community and Family Medicine & 4 & $3 \%$ & 4 & $3 \%$ \\
\hline $\begin{array}{l}\text { Community Health and Family } \\
\text { Medicine }\end{array}$ & 1 & $1 \%$ & 2 & $1 \%$ \\
\hline $\begin{array}{l}\text { Community Medicine and Health } \\
\text { Care }\end{array}$ & 1 & $1 \%$ & 0 & $0 \%$ \\
\hline Family and Community Medicine & 35 & $24 \%$ & 44 & $29 \%$ \\
\hline $\begin{array}{l}\text { Family Medicine and Community } \\
\text { Health }\end{array}$ & 7 & $5 \%$ & 10 & $6 \%$ \\
\hline $\begin{array}{l}\text { Family Medicine, Preventive Medi- } \\
\text { cine and Community Health }\end{array}$ & 1 & $1 \%$ & 0 & $0 \%$ \\
\hline $\begin{array}{l}\text { Family, Community and Preventive } \\
\text { Medicine }\end{array}$ & 1 & $1 \%$ & 2 & $1 \%$ \\
\hline Family and Community Health & 0 & $0 \%$ & 1 & $1 \%$ \\
\hline Family and Preventive Medicine & 8 & $6 \%$ & 5 & $3 \%$ \\
\hline $\begin{array}{l}\text { Family Medicine and Population } \\
\text { Health }\end{array}$ & 1 & $1 \%$ & 1 & $1 \%$ \\
\hline $\begin{array}{l}\text { Family, Population } \& \text { Preventive } \\
\text { Medicine }\end{array}$ & 0 & $0 \%$ & 1 & $1 \%$ \\
\hline $\begin{array}{l}\text { Family Medicine and Public Health } \\
\text { Sciences }\end{array}$ & 1 & $1 \%$ & 1 & $1 \%$ \\
\hline Family Medicine and Public Health & 0 & $0 \%$ & 1 & $1 \%$ \\
\hline Family Medicine and Rural Health & 1 & $1 \%$ & 1 & $1 \%$ \\
\hline $\begin{array}{l}\text { Family Medicine and Osteopathic } \\
\text { Manipulative Medicine }\end{array}$ & 0 & $0 \%$ & 1 & $1 \%$ \\
\hline $\begin{array}{l}\text { Family Medicine and Comprehen- } \\
\text { sive Care }\end{array}$ & 0 & $0 \%$ & 1 & $1 \%$ \\
\hline Family, Internal, and Rural Medicine & 0 & $0 \%$ & 1 & $1 \%$ \\
\hline Family and Geriatric Medicine & 1 & $1 \%$ & 1 & $1 \%$ \\
\hline Family and Social Medicine & 1 & $1 \%$ & 1 & $1 \%$ \\
\hline
\end{tabular}

